\title{
AVALIAÇÃO DA QUALIDADE OPERACIONAL EM CINCO SUBSISTEMAS DE COLHEITA FLORESTAL ${ }^{1}$
}

Laércio Antônio Gonçalves Jacovine ${ }^{2}$, Carlos Cardoso Machado², Amaury Paulo de Souza ${ }^{2}$, Helio Garcia Leite $^{2}$ e Luciano José Minetti ${ }^{3}$

\begin{abstract}
RESUMO - A qualidade das operações foi avaliada em cinco subsistemas de colheita, adotados por empresas florestais brasileiras que utilizam madeira para produção de celulose de fibras curtas e painéis. O sistema empregado pelas empresas foi o de toras curtas, e os subsistemas avaliados foram: 1) "harvester" + "forwarder", 2) "slingshot" + "forwarder", 3) motosserra + manual, 4) motosserra + "forwarder" e 5) motosserra + guincho. Os itens avaliados foram os seguintes: altura de cepas e da faixa de fratura; cepas danificadas, com espeto, cobertas pela galhada e rachadas; e comprimento de toras e toras com gancho. Nenhum dos subsistemas avaliados atendeu a todas as especificações de qualidade dos itens avaliados, podendo-se inferir que a qualidade das operações precisa ser melhorada em todos eles. Não ficou evidenciado que um subsistema seja melhor que o outro, pois em alguns itens um subsistema foi melhor, mas em outro já se apresentou pior. Independentemente do subsistema utilizado, o estabelecimento de controles é fundamental para identificação e solução de problemas que afetam a qualidade das operações que compõem a colheita florestal.
\end{abstract}

Palavras-chave: Colheita florestal, controle de qualidade e floresta plantada.

\section{EVALUATION OF THE OPERATIONAL QUALITY IN FIVE SUBSYSTEMS OF FOREST HARVESTING}

\begin{abstract}
Operational quality was assessed in five harvesting subsystems adopted by Brazilian forest companies that use wood for cellulose and fiber sheets. The short log system is used by the companies and the subsystems are 1) Harvest + Forwarder; 2) Slingshot + Forwarder; 3) Chainsaw + Manual; 4) Chainsaw + Forwarder and 5) Chainsaw and tow. Stump height and fracture range, damaged stumps with splinters covered by branches and split; log length and logs with 'hooks' were assessed to obtain operational quality. No subsystem met all the quality specifications for the items assessed, and it can be inferred that the operational quality should be improved in all of them. No subsystem was shown to be better than another, as one was better in some items but worse in others. Regardless of the subsystem used, control setting is fundamental to identify and solve the problems that affect the quality of operations in forest harvesting.
\end{abstract}

Key words: Harvesting forest, quality control, planted forest.

\section{INTRODUÇÃO}

Controle de qualidade $(C Q)$ é um sistema amplo, complexo e abrange todos os setores de uma empresa, em um esforço comum e cooperativo, visando estabelecer, melhorar e assegurar a qualidade da produção, em níveis econômicos, para satisfazer os desejos dos consumidores (LOURENÇO FILHO, 1981). Para Campos (1992), é um modelo gerencial centrado no controle do processo, tendo como meta a satisfação das necessidades das pessoas.

\footnotetext{
${ }^{1}$ Recebido em 20.04.2004 e aceito para publicação em 20.04.2005.

${ }^{2}$ Departamento de Engenharia Florestal da UFV, 36570-000 Viçosa-MG. E-mail: <jacovine@ufv.br>

${ }^{3}$ Departamento de Engenharia Elétrica e de Produção da UFV, 36570-000 Viçosa-MG.
} 
Diferentemente da inspeção tradicional que verificava a qualidade do produto acabado, o moderno controle de qualidade deve atuar em todas as fases do processo produtivo: sua diretriz é evitar a produção de itens de qualidade insatisfatória, em lugar de separálos somente no final da produção (LOURENÇO FILHO, 1981). Segundo Kume (1993), no controle de qualidade tenta-se descobrir fatos através da coleta de dados, e, então, toma-se a ação necessária com base nestes. Os dados são obtidos medindo-se as características de uma amostra, e, com esses dados, faz-se uma inferência sobre a população e aplicam-se ações corretivas, se necessário.

O controle de qualidade nas indústrias brasileiras, principalmente nas exportadoras, foi incorporado rapidamente, em razão de exigências do mercado. Segundo Trindade (2001), desde o final da década de 1980 as indústrias brasileiras iniciaram um grande esforço na busca da certificação da qualidade pela série ISO 9000. Garlipp (1995) afirmou que tanto a certificação da qualidade quanto a ambiental passam a ser condição de sobrevivência e que $68 \%$ dos americanos, por exemplo, estão propensos a pagar 10 a $15 \%$ pelos produtos que atendam a essas exigências. No Brasil, as empresas responderam rapidamente, pois no início dos anos de 1990 o número de certificações não passava de 13, indo para mais de 3.500 em 2000 (BANAS, 1998; TRINDADE, 2001).

No setor florestal, entretanto, essa incorporação aconteceu, e está acontecendo, de forma mais lenta. A primeira proposta de controle de qualidade no setor florestal foi elaborada por Freitas et al. (1980), que se basearam em auditorias com o sentido policialesco. Esse sistema, segundo Trindade (1993), evoluiu para o conceito de autocontrole, em que o próprio pessoal operacional avalia suas atividades. Ultimamente, algumas empresas florestais já identificaram oportunidades de melhoria no processo produtivo e estão implantando sistemas de gestão da qualidade na indústria, bem como nas atividades desenvolvidas nas áreas de plantio.

Entre as atividades florestais, a colheita florestal, por ser a atividade que mais onera o custo de produção da madeira no Brasil (TANAKA, 1986; REZENDE et al., 1983; BAGIOe STÖHR, 1978), merece atenção especial das empresas, de forma que suas operações sejam otimizadas e a melhoria da qualidade seja alcançada em todas as etapas do processo, de forma contínua.
Na atividade de colheita são empregados vários subsistemas, cabendo a cada empresa optar pelo mais adequado às suas condições. No Brasil, certas empresas estão adquirindo máquinas e colocando-as em operação sem um estudo prévio e acompanhamento mais amplo, gerando, entre outras coisas, baixa qualidade das operações.

A melhoria da qualidade das operações de colheita só pode ser obtida se houver um sistema de controle de qualidade implantado na empresa. Vários estudos sobre controle de qualidade na área industrial tem sido divulgados, porém, na área florestal, poucos trabalhos têm mostrado aplicações de ferramentas da qualidade. Dessa forma, realizou-se esta pesquisa, com o objetivo principal de avaliar a qualidade das operações de cinco subsistemas de colheita empregados por duas empresas florestais brasileiras, sendo uma produtora de celulose de fibra curta e a outra de painéis de madeira, situadas na Região Sudeste do Brasil.

\section{MATERIAL E MÉTODOS}

\subsection{Descrição dos subsistemas}

No presente estudo foram avaliados cinco subsistemas utilizados por duas empresas florestais, sendo uma produtora de celulose e a outra de painéis de madeira, conforme descrito no Quadro 1.

Segundo Machado (1985), citado por Machado (2002), os subsistemas estudados são classificados como de toras curtas (Quadro 1). No subsistema 1 (HV + FW), o corte é feito com o "harvester" e a extração, com o "forwarder". O "harvester" processa as árvores individualmente, ou seja, cada árvore é derrubada, desgalhada, destopada e traçada separadamente. O eito de corte é composto de três a cinco, mas na maioria das vezes por quatro linhas de árvores. O tombamento destas após o abate é feito no sentido das árvores em pé, sendo sua base puxada para a área já cortada. As árvores são seccionadas em toras de $6 \mathrm{~m}$ e dispostas perpendicularmente à linha de plantio, formando feixes que ficam distribuídos na área, prontos para serem extraídos. As pontas das árvores e os galhos são colocados nas entrelinhas, por onde irá passar o "forwarder". Este extrai a madeira preparada pelo "harvester", dispondo-a em pilhas à beira do talhão, num trabalho conhecido como baldeio. 
Quadro 1 - Descrição dos equipamentos utilizados no corte e na extração nos subsistemas de colheita avaliados

Table 1 -Description of the equipment used in the cutting and extraction for the assessed harvesting subsyistem

\begin{tabular}{ccc}
\hline Subsistemas & Corte & Extração \\
\hline 1 & "Harvester" (HV) & "Forwarder" (FW) \\
2 & "Slingshot" (SLS) & "Forwarder" (FW) \\
3 & Motosserra (MS) & Tombamento Manual (MA) \\
4 & Motosserra (MS) & "Forwarder" (FW) \\
5 & Motosserra (MS) & Guincho (GUI) \\
\hline
\end{tabular}

No subsistema 2 (SLS + FW), o corte é feito pelo "slingshot" e a extração, pelo "forwarder". O "slingshot" executa o corte de cada árvore individualmente, acumulando a madeira no seu cabeçote até formar um feixe de geralmente oito árvores. O eito de corte é composto de três a cinco, mas na maioria das vezes por quatro linhas de árvores. Em seguida, esse feixe é tombado no sentido do aceiro, formando um ângulo de 45 a $60^{\circ}$ em relação ao equipamento. As árvores do feixe são todas processadas (desgalhadas, traçadas e destopadas) de uma só vez, com comprimento de $6 \mathrm{~m}$, sendo as pontas não aproveitáveis depositadas nas entrelinhas, por onde irá passar o "forwarder", que realizará a operação de extração, da mesma forma descrita para o subsistema $1(\mathrm{HV}+\mathrm{FW})$.

O tipo de rodados dos equipamentos "Harvester" e o "Slingshot", utilizados pela empresa estudada, era de esteiras e o do "Forwarder", de pneu.

A empresa estudada que emprega os dois subsistemas descritos anteriormente localiza-se na Região Sudeste, e a topografia de suas áreas é plana. Já a outra empresa que utiliza os três subsistemas descritos a seguir localiza-se em região montanhosa.

No subsistema 3 (MS + MA), o corte é feito por motosserra e a extração, manualmente. $\mathrm{O}$ motosserrista realiza a derrubada das árvores, no sentido das linhas de plantio (morro abaixo) e faz o desgalhamento, traçamento e destopamento. As toras, com comprimento de 2,20 m, não sofrem qualquer movimentação ou arranjamento antes da extração. A extração é feita por tombamento manual até a beirada da estrada. A seguir os operários fazem uma pilha contínua de madeira na margem da estrada, situada do lado contrário do corte do barranco do talhão explorado.

No subsistema 4 (MS + FW), o corte é feito por motosserra e a extração, pelo "forwarder". O corte é feito de modo semelhante àquele descrito no subsistema 3 (MS + MA). A única diferença é que os feixes são formados manualmente no interior do talhão e as toras, dispostas no sentido das linhas de plantio, para facilitar a formação das pilhas. O "forwarder" realiza a operação de extração da mesma forma que no subsistema 1 (HV $+\mathrm{FW}$ ).

No subsistema 5 (MS + GUI), o corte é feito por motosserra e a extração, pelo guincho-arrastador acoplado a um trator agrícola. As árvores são derrubadas no sentido contrário às linhas de plantio, para facilitar a formação de pilhas de madeira e posterior arraste por meio de um guincho. As toras são colocadas sobre "travesseiros", formados por toras atravessadas e escoradas por duas estacas previamente fixadas no solo. Um cabo de aço é amarrado à pilha de madeira por um ajudante, a qual é arrastada até a beira do talhão pelo trator, que possui um tambor com cabo de aço de 5/8" acoplado à tomada de potência (TDP). Em seguida, a madeira é disposta sobre suporte situado abaixo do rolo, e o trator desloca as toras para a pilha de armazenamento.

O tempo médio de trabalho na colheita florestal dos operadores, nas empresas estudadas, foi de 26 meses.

\subsection{Especificações do comprimentos e dos diâmetros das toras}

As especificações para comprimento e diâmetro das toras considerados como padrão no estudo foram aquelas estabelecidas pelas empresas (Quadro 2).

Os subsistemas 1 e 2 são utilizados em região plana, e as toras são cortadas com $6 \mathrm{~m}$ de comprimento. Os subsistemas 3, 4 e 5 são utilizados em região montanhosa, sendo as toras cortadas com 2,20 m de comprimento.

As especificações mínimas para aproveitamento das toras são determinadas pelas empresas em função do destino final da madeira. Para a fabricação de painéis, utilizando os subsistemas 1 e 2, são aproveitadas toras com mais de 4,0 cm de diâmetro e comprimento maior que 2,50 m. Já para a fabricação de celulose, utilizando os subsistemas 3, 4 e 5, são aproveitadas toras com mais de $6,0 \mathrm{~cm}$ de diâmetro e com comprimento maior que $1,50 \mathrm{~m}$. As medidas de diâmetro referem-se à ponta mais fina da tora.

R. Árvore, Viçosa-MG, v.29, n.3, p.391-400, 2005 
Quadro 2 - Padrões de comprimento e de diâmetro das toras especificados pelas empresas para aproveitamento da madeira Table 2 - Log length and diameter patterns specified by the companies for wood use

\begin{tabular}{lccc}
\hline Subsistemas & Comprimento Padrão (metro) & Comprimento Mínimo (metro) & Diâmetro Mínimo (centímetro) \\
\hline 1 (HV + FW) & 6,00 & 2,50 & 4,0 \\
2 (SLS + FW) & 6,00 & 2,50 & 4,0 \\
$3($ MS + MA) & 2,20 & 1,50 & 6,0 \\
$4($ MS + FW) & 2,20 & 1,50 & 6,0 \\
5 (MS + GUI) & 2,20 & 1,50 & 6,0 \\
\hline
\end{tabular}

\subsection{Itens avaliados para determinação da qualidade das operações}

Os itens avaliados nos cinco subsistemas foram os seguintes:

a) Altura de cepas - Mediu-se a altura de 50 cepas, duas vezes ao dia (uma pela manhã e outra à tarde), durante cinco dias, perfazendo um total de 500 cepas avaliadas. $\mathrm{O}$ caminhamento adotado foi em linhas seqüenciais, sendo medidas 10 cepas em cada linha até completar 50 cepas. A avaliação, em cada dia, foi feita em área que tinha sido cortada no dia anterior. A altura da cepa foi medida, tomando-se como referência a distância do solo ao topo da cepa. No caso de cepas cortadas em bisel e com faixa de fratura, a medida tomada foi a altura média, que correspondeu ao intervalo médio entre a maior e a menor altura.

b) Altura da faixa de fratura - A faixa de fratura corresponde à diferença de altura entre o corte da base e o corte de abate. $O$ padrão estabelecido foi uma faixa de fratura de 1 a $3 \mathrm{~cm}$. Para medição da altura da fratura nos subsistemas 3, 4 e 5, empregaramse o mesmo método e as mesmas parcelas utilizadas para medição da altura de cepas. Nos susbsistemas 1 e 2 não foi avaliado esse item, pois a árvore é derrubada com apenas um corte, não deixando a faixa de fratura.

c) Cepas danificadas, com espetos, cobertas e rachadas - Foram lançadas 25 unidades de amostra de 20 cepas, distribuídas aleatoriamente após a extração da madeira. Os parâmetros levados em consideração em cada item avaliado foram os seguintes:

- Cepas danificadas - Cepas com mais de 30\% de sua área basal descascada ou lascada. A avaliação foi feita por meio de observação visual.

- Cepas com espeto - Cepas com lascas desprendidas da tora e que ficaram presas a ela.

- Cepa coberta pela galhada - Cepas que se encontravam totalmente sombreadas pelos galhos e pontas das árvores cortadas, juntamente com suas folhas.

- Cepa rachada - Cepas que apresentavam fenda em toda a sua superfície.

d) Comprimento de toras - Mediu-se o comprimento de 50 toras, duas vezes ao dia, durante cinco dias, perfazendo um total de 500 toras. As 50 toras foram escolhidas aleatoriamente, sendo tomadas cinco delas em cada feixe, e o sentido do caminhamento foi contrário às linhas das cepas.

e) Toras com ganchos - Lançaram-se 25 amostras com 20 toras, distribuídas aleatoriamente na área, após o traçamento das árvores. Considerou-se tora defeituosa aquela que apresentou gancho com mais de $5 \mathrm{~cm}$ de comprimento.

\subsection{Limites de especificação}

As especificações utilizadas neste estudo foram estabelecidas de acordo com os padrões utilizados pelas empresas e os critérios técnicos para os sistemas utilizados.

A especificação para altura de cepas considerada foi de 6 a $10 \mathrm{~cm}$. Essa altura foi estabelecida pela empresa, e justifica-se, já que os povoamentos estão com a idade em torno de 7 anos, e suas brotações serão conduzidas para um segundo corte. Já a especificação para comprimento de toras foi de 5,20 a 6,00 m para os subsistemas 1 e 2 . O comprimento das toras nesse intervalo foi estabelecido pela empresa, e justifica-se pela necessidade da sua adequação nos compartimentos da carroceria dos veículos utilizados no transporte. Toras fora desses limites dificultam o carregamento (toras maiores) ou, até mesmo, podem cair durante o transporte (toras menores). O comprimento de 2,10 a 2,30 m nos subsistemas 3,4 e 5 foi estabelecido de acordo com o padrão operacional da empresa.

Os resultados encontrados foram comparados com os limites especificados, verificando-se o atendimento 
ou não da especificação. Quando não atendia, classificouse em acima e abaixo da especificação.

\subsection{Avaliação por variáveis e por atributos}

A avaliação por variáveis foi utilizada nos itens altura de cepas e comprimentos, pois a sua qualidade é mensurável ou medida diretamente. Nos outros itens restantes, utilizou-se a avaliação por atributos, em que se procurou verificar se cada unidade da amostra atendia ou não a uma característica, sendo denominada de fora ou dentro da especificação.

Para análise dos dados foi utilizada uma estatística descritiva.

\section{RESULTADOS E DISCUSSÃO}

A qualidade das operações dos cinco subsistemas de colheita florestal foi obtida por meio dos itens avaliados. As informações referem-se apenas ao período de levantamento dos dados.

\subsection{Altura das cepas}

Para todos os subsistemas avaliados, verificouse que a especificação não foi atendida, dada a presença de cepas com alturas nas classes superiores e inferiores ao padrão estabelecido (Quadro 3). Jacovine et al. (1999), estudando o sistema semimecanizado, encontraram um volume de 1,56 estéreo/hectare de perda de madeira referente a cortes acima da altura especificada pela empresa.

O subsistema que apresentou maior porcentagem de dados atendendo à especificação foi o subsistema $2(\mathrm{SLS}+\mathrm{FW})$, totalizando $49,8 \%$ dos dados. Cortes abaixo da especificação foram mais evidentes no subsistema 3 (MS + MA), com 80,2\% dos dados apresentando altura inferior a $6 \mathrm{~cm}$. Acima da especificação, o subsistema 1 ( $\mathrm{HV}+\mathrm{FW})$ se destacou entre os subsistemas avaliados, com 58,8\% dos dados.
Ao comparar os subsistemas 1 e 2, verificou-se que o primeiro apresentou a maioria dos dados acima da especificação e o segundo, grande parte dos dados abaixo da especificação e até mesmo abaixo do nível do solo, o que promove desgaste anormal do disco de corte. A questão da variação da altura de corte das cepas está relacionada, entre outros fatores, ao treinamento e à habilidade dos operadores.

Para controlar a altura de cepas nos dois sistemas referidos anteriormente, poder-se-ia adaptar uma barra ajustável na base do equipamento com altura correspondente à especificação. O operador necessitaria apenas encostar a base do equipamento no solo e acionar o sistema de corte, para que a árvore fosse cortada na altura desejável. Essa barra poderia ser ajustável, de forma que, quando forem requeridos cortes em alturas diferentes, possa ser regulada para atender à especificação.

Nos subsistemas 3, 4 e 5, apesar de a derrubada ser realizada com motosserra em todos eles, houve variação entre estes. Os subsistemas 3 (MS + MA) e 5 (MS + GUI) apresentaram a maioria (80,2 e 43,0\%, respectivamente) das cepas, com altura abaixo da especificação. Já o subsistema 4 (MS + FW) apresentou a maioria $(44,8 \%)$ das alturas dentro da especificação.

A explicação que se pode dar para a diferença entre os subsistemas é que cepas com maior altura prejudicam a extração manual e com guincho, havendo, assim, maior cobrança por parte dos encarregados e, até mesmo, entre os funcionários do corte e da extração, para que as cepas fiquem com menores alturas. Se os tocos estiverem muito altos, a rolagem das toras é dificultada na extração manual. Já na extração com guincho os feixes, ao serem arrastados, agarram nos tocos, dificultando o seu tracionamento e, até mesmo, causando o seu desmanche. Assim, há uma cobrança entre os operários de corte e os de extração, e maior rigor na cobrança pelos chefes de turma, para que as cepas fiquem dentro da altura especificada.

Quadro 3 - Porcentagem de cepas com altura dentro, abaixo e acima da especificação, em cinco subsistemas de colheita Table 3 - Percentage of stumps with height within, below or above the specification for five harvesting subsystems

\begin{tabular}{lccc}
\hline Subsistemas & Abaixo da Especificação (\%) & Dentro da Especificação (\%) & Acima da Especificação (\%) \\
\hline 1 (HV + FW) & 6,8 & 34,4 & 58,8 \\
2 (SLS + FW) & 37,2 & 49,8 & 13,0 \\
3 (MS + MA) & 80,2 & 14,4 & 5,4 \\
4 (MS + FW) & 12,8 & 44,8 & 42,4 \\
5 (MS + GUI) & 43,0 & 41,2 & 15,8 \\
\hline
\end{tabular}


No subsistema 4 (MS + FW), como a extração é realizada com o "forwarder", a altura de cepas afeta em menor intensidade a operação, havendo, por isso, menor preocupação com a altura de cepas. Isso ficou evidente ao verificar-se que nesse sistema, apesar de a maioria dos dados $(44,8 \%)$ estar dentro da especificação, ainda foram encontrados $42,4 \%$ dos dados acima da especificação.

\subsection{Altura da faixa de fratura}

A especificação não é atendida para os subsistemas avaliados, dada a predominância de faixas de fratura com alturas nas classes superiores e inferiores ao padrão recomendável (Quadro 4).

$\mathrm{O}$ atendimento à especificação da altura da faixa de fratura é importante no direcionamento de queda da árvore, na prevenção de acidentes e qualidade da tora. O corte de abate feito no mesmo nível ou abaixo do corte de base pode inverter a direção de queda da árvore, dificultando a realização das operações subseqüentes e aumentando o risco de acidentes. Já o corte de abate muito acima do corte de base poderá causar um lascamento da árvore e formar o que se denomina "cadeira de barbeiro", aumentando, também, o risco de acidente, além de diminuir a qualidade da tora.

O subsistema 3 foi o que apresentou menor porcentagem de cepas com altura de fratura dentro da especificação. Esse subsistema é empregado em áreas de maior declividade, em que a extração é feita manualmente, havendo, assim, menor preocupação do operador quanto ao direcionamento de queda das árvores, pois as toras, após o traçamento, não sofrerão nenhuma movimentação ou arrumação para a extração.

\subsection{Cepas danificadas}

No subsistema 3 (MS + MA), como a extração é manual e não há contato dos pneus das máquinas e dos feixes de madeira com a cepa, não foram encontradas cepas danificadas (Quadro 5).

Nos subsistemas 1, 2, 4 e 5, é necessário diminuir essa não conformidade, pois, mesmo havendo algumas cepas que brotam apesar de estarem danificadas, certamente haverá algum prejuízo na emissão, sobrevivência e crescimento dos brotos. Estudo feito por Machado et al. (1990) indicou que $14,82 \%$ das cepas atingidas durante o arraste florestal não brotaram, em virtude dos danos mecânicos. Também foi verificado que os danos às cepas afetaram o crescimento em altura da brotação até o décimo mês. Dessa forma, são necessárias medidas que amenizem o problema dos danos às cepas, quando se pensa em conduzir a floresta no sistema de talhadia. Quanto ao "forwarder" poderia, por exemplo, evitar manobras no interior do talhão e melhorar o arranjamento dos feixes, deixando a linha livre de empecilhos, para evitar desvios de toras existentes na linha e, conseqüentemente, passagem em cima das cepas. Já o arraste de feixes com o guincho arrastador não se vislumbra, inicialmente, nenhuma medida que possa minimizar o problema, mas entende-se que, em função dos aspectos ambientais negativos provocados por essa operação, assim que se viabilizar outra forma de extração aplicável em áreas de acidentadas, o seu uso poderá ser diminuído ou descartado.

Quadro 5 - Porcentagem média de cepas danificadas, em cinco subsistemas de colheita

Table 5-Mean percentage of damaged stumps for five harvesting subsystems

\begin{tabular}{lc}
\hline Subsistemas & Cepas Danificadas $(\%)$ \\
\hline $1(\mathrm{HV}+\mathrm{FW})$ & 18,8 \\
$2(\mathrm{SLS}+\mathrm{FW})$ & 17,2 \\
$3(\mathrm{MS}+\mathrm{MA})$ & 0 \\
$4(\mathrm{MS}+\mathrm{FW})$ & 16,2 \\
$5(\mathrm{MS}+\mathrm{GUI})$ & 11,6 \\
\hline
\end{tabular}

Quadro 4 - Porcentagem de cepas com altura de fratura dentro, abaixo e acima da especificação, em três subsistemas de colheita

Table 4-Percentage of stumps with fracture height, within, below, and above the specification for three harvesting subsystems

\begin{tabular}{lccc}
\hline Subsistemas & Abaixo da Especificação (\%) & Dentro da Especificação (\%) & Acima da Especificação (\%) \\
\hline $3($ MS + MA) & 3,0 & 8,6 & 88,4 \\
$4($ MS + FW) & 15,2 & 42,8 & 42,0 \\
$5($ MS + TMO) & 34,4 & 36,0 & 29,6 \\
\hline
\end{tabular}

R. Árvore, Viçosa-MG, v.29, n.3, p.391-400, 2005 


\subsection{Cepas com espeto}

O subsistema $2($ SLS + FW) não apresentou cepas com espeto, dada a robustez do conjunto de corte do "slingshot", que realiza o corte de forma muito rápida e contínua (Quadro 6). Nos outros subsistemas, a porcentagem encontrada de cepas com espeto pode ser considerada baixa. Jacovine (1996), em seu estudo, também encontrou baixa porcentagem $(4,18 \%)$ de cepas com presença de espeto, podendo-se afirmar que essa anormalidade afeta pouco a qualidade das operações da colheita florestal.

\subsection{Cepas cobertas}

A porcentagem de cepas cobertas variou de 4 a $8,2 \%$ (Quadro 7). A maior quantidade de cepas cobertas foi encontrada no subsistema 3 (MS + MA), o que pode ser explicado pelo fato de que, nesse subsistema, dá-se menos importância ao arranjamento da galhada, em uma linha específica, por ser a extração realizada manualmente e, a princípio, entender-se que a galhada não atrapalha a operação. Além disso, em função da alta declividade das áreas onde é empregado este subsistema, a galhada tende a se acumular nas cepas, pois estas servem de ancoramento.

Quadro 6 - Porcentagem média de cepas com espeto, em cinco subsistemas de colheita

Table 6-Mean percentage of stumps with splinters, for five harvesting subsystems

\begin{tabular}{|c|c|}
\hline Subsistemas & Cepas com Espeto (\%) \\
\hline $1(\mathrm{HV}+\mathrm{FW})$ & 4,0 \\
\hline $2(\mathrm{SLS}+\mathrm{FW})$ & 0 \\
\hline $3(\mathrm{MS}+\mathrm{MA})$ & 1,4 \\
\hline $4(\mathrm{MS}+\mathrm{FW})$ & 1,8 \\
\hline $5(\mathrm{MS}+\mathrm{GUI})$ & 2,8 \\
\hline
\end{tabular}

Quadro 7 - Porcentagem média de cepas cobertas, em cinco subsistemas de colheita

Table 7-Mean percentage of covered stumps, for five harvesting subsystems

\begin{tabular}{lc}
\hline \multicolumn{1}{c}{ Subsistemas } & Cepas Cobertas $(\%)$ \\
\hline $1(\mathrm{HV}+\mathrm{FW})$ & 4,0 \\
$2(\mathrm{SLS}+\mathrm{FW})$ & 6,0 \\
3 (MS + MA) & 8,2 \\
$4(\mathrm{MS}+\mathrm{FW})$ & 4,8 \\
$5(\mathrm{MS}+\mathrm{GUI})$ & 4,8 \\
\hline
\end{tabular}

A cobertura das cepas pela galhada irá trazer prejuízos à brotação e o desenvolvimento destas. Em alguns casos, o broto emitido pela cepa fica totalmente sombreado, resultando em um broto tenro e com menores chances de sobrevivência, ao ser exposto à luminosidade.

\subsection{Cepa rachada}

Nos subsistemas 3, 4 e 5, em que a derrubada é feita com motosserra, não foi encontrada esta nãoconformidade (Quadro 8). As porcentagens médias de cepas rachadas encontradas nos subsistemas $1(3,2 \%)$ e $2(2,0 \%)$ podem ser consideradas baixas. Jacovine (1996) encontrou, em seu estudo, para o corte com motosserra, uma porcentagem bem maior $(12,36 \%)$ de cepas rachadas.

O rachamento das cepas promovido pelo "harvester" e "slingshot" se deve a um descontrole no tempo de corte e no levantamento do cabeçote. O operador, ao acionar o comando para levantar o cabeçote, antes do corte completo da árvore, irá promover uma tensão na parte presa à raiz, o que ocasiona o rachamento. Essa anormalidade pode ser corrigida com o treinamento dos operadores dos equipamentos.

A medida que pode ser adotada para diminuir ou eliminar essa anormalidade é a maior cobrança dos operadores para que estes passem a erguer ou inclinar o cabeçote somente após o corte completo da árvore.

\subsection{Comprimento de toras}

Em todos os subsistemas avaliados, verificouse que a especificação não foi atendida, dada a presença de toras com comprimentos nas classes superiores e inferiores ao padrão estabelecido (Quadro 9).

Quadro 8 - Porcentagem média de cepas rachadas, em cinco subsistemas de colheita

Table 8-Mean percentage of cracked logs, for five harvesting subsystems

\begin{tabular}{lc}
\hline \multicolumn{1}{c}{ Subsistemas } & Cepas Rachadas $(\%)$ \\
\hline $1(\mathrm{HV}+\mathrm{FW})$ & 3,2 \\
$2(\mathrm{SLS}+\mathrm{FW})$ & 2,0 \\
$3(\mathrm{MS}+\mathrm{MA})$ & 0 \\
$4(\mathrm{MS}+\mathrm{FW})$ & 0 \\
$5(\mathrm{MS}+\mathrm{GUI})$ & 0 \\
\hline
\end{tabular}


Quadro 9 - Porcentagem média de toras com comprimento dentro, abaixo e acima da especificação, em cinco subsistemas de colheita

Table 9 - Mean percentage of logs with length within, below and above the specification, for five harvesting subsystems

\begin{tabular}{lcccc}
\hline Subsistemas & $\begin{array}{c}\text { Especificação } \\
(\mathrm{m})\end{array}$ & $\begin{array}{c}\text { Abaixo da Especificação } \\
(\%)\end{array}$ & $\begin{array}{c}\text { Dentro da Especificação } \\
(\%)\end{array}$ & $\begin{array}{c}\text { Acima da Especificação } \\
(\%)\end{array}$ \\
\hline $1(\mathrm{HV}+\mathrm{FW})$ & 5,20 a 6,00 & 25,6 & 67,4 & 7,0 \\
$2(\mathrm{SLS}+\mathrm{FW})$ & 5,20 a 6,00 & 14,0 & 59,6 & 26,4 \\
$3(\mathrm{MS}+\mathrm{MA})$ & 2,10 a 2,30 & 11,6 & 73,6 & 14,8 \\
$4(\mathrm{MS}+\mathrm{FW})$ & 2,10 a 2,30 & 4,2 & 81,4 & 14,4 \\
$5(\mathrm{MS}+\mathrm{GUI})$ & 2,10 a 2,30 & 8,0 & 79,6 & 12,4 \\
\hline
\end{tabular}

Vale ressaltar que no subsistema $1(\mathrm{HV}+\mathrm{FW})$, mesmo o "harvester" possuindo um sistema automático de medição do comprimento da tora, a operação estava despadronizada, sendo encontrado, principalmente, toras com comprimento abaixo da especificação. Geralmente isso ocorre em razão de os operadores não perceberem um problema mecânico ocorrido no sistema que controla o comprimento de toras do equipamento. Esse problema pode ser controlado por meio de uma rotina de aferição periódica do comprimento de toras. Outro aspecto operacional que influencia o comprimento da tora é a parada no tracionamento do fuste em virtude da existência de alguns obstáculos, por exemplo galho mais grosso, em que o operador precisa parar o movimento do rolo, retorná-lo e só depois voltar a tracionar o fuste. Esse movimento de vai-e-vem altera a medição do fuste a ser seccionado pelo equipamento.

No subsistema 2 (SLS + FW) foram encontradas, principalmente, toras com comprimentos acima da especificação. A não-conformidade apresentada nesse subsistema é explicada pelo sistema de tracionamento e corte dos feixes, que não permite um controle perfeito dessa variável. As toras existentes no feixe não são tracionadas uniformemente e, ao se fazer o corte, aquelas que não foram tracionadas juntamente com as outras são traçadas com um comprimento menor. No entanto, o operador, ao tentar ajustar o feixe para compensar o comprimento das toras que não foram tracionadas completamente, acaba por permitir maior avanço do feixe, fazendo que algumas toras fiquem com comprimento maior que o padrão estabelecido.

Os subsistemas 3, 4 e 5 apresentaram maior porcentagem de toras dentro da especificação, mas, mesmo assim, há necessidade de melhoria na qualidade da padronização do comprimento de toras.

Nos subsistemas 3, 4 e 5, em que se empregou a motosserra, foi observado que o traçamento, em termos de padronização, se equipara, ou até supera, os equipamentos que possuem maior grau de tecnologia e que são empregados nos outros dois subsistemas. Portanto, em qualquer dos subsistema avaliados é necessário haver melhoria da qualidade na padronização do comprimento das toras, pois a variação existente pode trazer as seguintes conseqüências:

- Ao se calcular o volume de madeira, quer seja na pilha, no caminhão ou no pátio, considera-se o comprimento estabelecido. Se o comprimento varia, o cálculo do volume pode indicar um valor abaixo ou acima do que realmente existe.

- O arranjamento da madeira na pilha ou no caminhão é dificultado, podendo entortar ou, até mesmo, causar a queda da pilha, em função dos espaços vazios entre as toras.

- Quando há grande ocorrência de toras maiores que o comprimento médio, o carregamento dos caminhões que transportam madeira em mais de um vão é prejudicado, pois as toras ficam com uma ponta para fora da pilha, atrapalhando o carregamento do próximo vão. Muitas vezes é necessário fazer o acerto da carga, com a grua vazia, ou com um toco preso na garra, que é arremessada contra a carga para se fazer o acerto, atrasando o carregamento. No entanto, toras menores que a distância entre os suportes em que é colocada a madeira poderão cair do caminhão, vindo a causar atraso na viagem se o motorista for recolher a tora ou, então, aumentar o risco de acidentes a outros veículos que circulam na estrada se a tora não for recolhida.

\subsection{Toras com gancho}

A porcentagem de toras com gancho encontrada variou de 2,0 a 6,0\% (Quadro 10). O maior número de toras com gancho foi encontrado no subsistema 5 (MS + GUI). A explicação para esse fato é que neste subsistema a derrubada é feita no sentido contrário à declividade 
do terreno e paralela ao aceiro, para facilitar a formação das pilhas para o arraste. Como nessas áreas a declividade é alta, as árvores deslizam e sobrepõem umas sobre as outras, de forma desordenada, o que dificulta a operação de desgalhamento.

O subsistema $1(\mathrm{HV}+\mathrm{FW})$ foi o que apresentou a menor porcentagem de toras com gancho. Nesse subsistema, as árvores são processadas individualmente, facilitando, com isso, o desgalhamento. Já no subsistema 2 (SLS + FW), em que o "slingshot" realiza o processamento de todo o feixe de árvores de uma só vez, o desgalhamento é de pior qualidade, resultando em $5,8 \%$ de toras com gancho.

Jacovine et al. (2001), em seu estudo, encontrou, no subsistema que utiliza o "Slingshot" no corte e o "Forwarder" na extração, uma perda média de madeira de 4,22 m³/ha, em razão da má qualidade na realização do desgalhamento.

Algumas medidas que podem ser tomadas para se melhorar o desgalhamento são descritas a seguir:

- Subsistema $1(\mathrm{HV}+\mathrm{FW})$ - Orientar aos operadores para que passem a tora mais uma vez no cabeçote, de forma que o galho seja cortado completamente.

- Subsistema 2 - Evitar processar feixes muito grandes.

- Subsistemas 3, 4 e 5-Orientar aos operadores de motosserra, para que façam o corte dos galhos o mais rente possível do tronco.

A má qualidade no desgalhamento pode afetar as operações posteriores, causando, principalmente:

- Diminuição do volume sólido de madeira transportada, em razão dos espaços vazios entre as toras, provocados pelos ganchos.

Quadro 10 - Porcentagem média de toras com gancho, em cinco subsistemas de colheita

Picture 10 - Mean percentage of logs with hook, for five harvest subsistems

\begin{tabular}{lc}
\hline Subsistemas & $\begin{array}{r}\text { Cepas com gancho fora } \\
\text { da especificação }(\%)\end{array}$ \\
\hline $1(\mathrm{HV}+\mathrm{FW})$ & 2,0 \\
2 (SLS + FW) & 5,8 \\
3 (MS + MA) & 3,6 \\
$4(\mathrm{MS}+\mathrm{FW})$ & 4,2 \\
5 (MS + GUI) & 6,0 \\
\hline
\end{tabular}

- Aumento do Fator de Empilhamento (FE) e, conseqüentemente, erro no cálculo do volume sólido de madeira.

- Entortamento ou queda da pilha do pátio ou do caminhão.

- Despadronização dos cavacos, podendo prejudicar, por exemplo, o processo fabril de celulose.

\section{CONCLUSÃO}

Com base nos resultados, pode-se concluir que:

- As especificações não são atendidas nos subsistemas avaliados, indicando a necessidade de melhoria do processo.

- A melhoria da qualidade do processo pode ser alcançada com investimento em treinamento dos operadores e com implantação de um sistema efetivo de controle.

- A avaliação de qualidade realizada periodicamente pelo próprio operador permite fazer correções necessárias durante a execução da operação.

- Não ficou evidenciado que, no geral, um subsistema seja melhor que o outro, pois em alguns itens um subsistema foi melhor, mas em outro já foi pior. A partir das não conformidades apontadas em qualquer dos subsistemas e considerando que as empresas possuem cultura organizacional voltada para a qualidade, podemse estabelecer mecanismos de controle da qualidade.

\section{REFERÊNCIAS BIBLIOGRÁFICAS}

BAGIO, A.J.; STÖHR, G.W.D. Resultados preliminares de um levantamento dos sistemas de exploração usados em florestas implantadas no sul do Brasil. Revista Floresta, v.9, n.2, p.7696, 1978.

BANAS, S.F. Sistema Brasileiro de Qualidade. Revista Banas Qualidade, v.1, n.1, 1998. (Edição Especial).

CAMPOS, V.F. TQC. Controle de qualidade total (no estilo japonês). Belo Horizonte: Fundação Cristiano Ottoni, 1992. 220p.

FREITAS, S.M. et al. Avaliação e controle de qualidade em florestas de eucaliptos. Piraciacaba: IPEF, 1980. 8p. (Circular Técnica, 91).

R. Árvore, Viçosa-MG, v.29, n.3, p.391-400, 2005 
GARLIPP, R.C.D. Certificação florestal. O Papel, v.8, n.1, p.129-35, 1995.

JACOVINE, L.A.G. Desenvolvimento de uma metodologia para avaliação dos custos de colheita florestal semimecanizada. 1996. 109p. Dissertação (Mestrado em Ciência Florestal). Universidade Federal de Viçosa, Viçosa, 1996.

JACOVINE, L.A.G. et al. Descrição de uma metodologia para valiação dos custos da qualidade na colheita florestal semimecanizada. Ciência Florestal, v.9, n.1, p. 143-160, 1999

JACOVINE, L. A. G. et al. Avaliação da perda de madeira em cinco subsistemas de colheita florestal. Revista Árvore, v. 25, n. 4, p. 463470, 2001.

KUME, H. Métodos estatísticos para melhoria da qualidade. São Paulo: Gente, 1993. 245p.

\section{LOURENÇO FILHO, R. C.B. Controle} estatístico de qualidade. Rio de Janeiro: Livros Técnicos e Científicos, 1981. 223p.
MACHADO, C.C. et al. Efeito da extração de madeira com guincho arrastador na brotação do Eucalyptus alba. Revista Árvore, v.14, n.1, p.55-60, 1990.

MACHADO, C.C. O setor florestal brasileiro. In: MACHADO, C.C. (Ed.).Colheita florestal. Viçosa, MG: UFV, 2002. 468p.

REZENDE, J.L.P.; PEREIRA, A.R.; OLIVEIRA, A.D. Espaçamento ótimo para a produção de madeira. Revista Árvore, v.7, n.1, p.30-43, 1983.

TANAKA, O.K. Exploração e transporte da cultura do eucalipto. Informe Agropecuário, v. 12, n.141, p.24-30, 1986.

TRINDADE, C. Desenvolvimento de um sistema de controle de qualidade para a atividade florestal. 1993. 164f. Dissertação (Mestrado em Ciência Florestal) - Universidade Federal de Viçosa, Viçosa, 1993.

TRINDADE, C. Análise da gestão da qualidade na empresa florestal. 2001. 140f. Tese (Doutorado em Ciência Florestal). Universidade Federal de Viçosa, Viçosa, 2001. 